\title{
Diagnóstico referente ao conhecimento dos principais atores sociais envolvidos no Geoparque da Quarta Colônia Aspirante UNESCO
}

\author{
Diagnosis regarding the knowledge of the main social actors involved in the Geopark of the Quarta \\ Colonia Aspirant UNESCO \\ Diagnóstico sobre el conocimiento de los principales actores sociales involucrados en el Geoparque \\ de la Quarta Colônia Aspirante UNESCO
}

Recebido: 12/11/2021 | Revisado: 26/11/2021 | Aceito: 29/11/2021 | Publicado: 10/12/2021

\author{
Silvia Guareschi Fioreze \\ ORCID: https://orcid.org/0000-0002-3026-2832 \\ Universidade Federal de Santa Maria, Brasil \\ E-mail: silviafioreze@yahoo.com.br \\ Cristiana Basso \\ ORCID: https://orcid.org/0000-0003-2001-0110 \\ Universidade Franciscana, Brasil \\ Universidade Federal de Santa Maria, Brasil \\ E-mail: cristianabasso1@gmail.com \\ Greici Cerezer Uliana \\ ORCID: https://orcid.org/0000-0001-8963-0807 \\ Universidade Federal de Santa Maria, Brasil \\ E-mail: greicinutricao@gmail.com \\ Mara Rúbia Doebber Da Cas \\ ORCID: https://orcid.org/0000-0003-0913-426X \\ Universidade Federal de Santa Maria, Brasil \\ E-mail: maradacas2@gmail.com \\ Luis Felipe Dias Lopes \\ ORCID: https://orcid.org/0000-0002-2438-0226 \\ Universidade Federal de Santa Maria, Brasil \\ E-mail: 1flopes67@yahoo.com.br \\ Neila Silvia Pereira dos Santos Richards \\ ORCID: https://orcid.org/0000-0001-6610-5567 \\ Universidade Federal de Santa Maria, Brasil \\ E-mail: neilarichardsprof@gmail.com
}

\begin{abstract}
Resumo
Geoparque pode ser definido como uma forma de proteção e promoção do patrimônio geológico e do desenvolvimento sustentável local. Este trabalho se propôs fazer um diagnóstico acerca do conhecimento dos principais atores sociais envolvidos no projeto Geoparque da Quarta Colônia Aspirante UNESCO, identificando aspectos referentes a seu perfil, suas expectativas quanto ao Geoparque, principalmente quanto ao potencial turístico, de hospedagem, lazer, artesanato e gastronomia local. Foram convidados a fazer parte da pesquisa empreendedores, artesãos, pessoas envolvidas com o turismo na região, além de residentes e/ou trabalhadores dos nove municípios integrantes da Quarta Colônia. Aos participantes foi disponibilizado um link que dava acesso direto a um questionário eletrônico elaborado na plataforma virtual Google Forms. Percebeu-se prevalência de servidores públicos; maioria com conhecimento sobre Geoproduto; quanto à existência de guiamento e informações turísticas a maioria respondeu não ter conhecimento; não haver placas de identificação turística coerente para atender aos turistas; haver transporte coletivo disponível; presença se artesanato inpirado na paisagem local; serviços de alimentação com ênfase na gastronomia regional; hospedagem rural e urbana disponíveis; diversas propostas de lazer. Com esse trabalho ficou ainda mais evidente o quanto a região da Quarta Colônia de imigração italiana está preparada para se tornar um Geoparque.
\end{abstract}

Palavras-chave: Geoparque; Geoproduto; Gastronomia regional.

\begin{abstract}
Geopark can be defined as a form of protection and promotion of geological heritage and local sustainable development. This work aimed to make a diagnosis of the knowledge of the main social actors involved in the Geopark project of the Quarta Colônia Aspiring UNESCO, identifying aspects related to their profile, their expectations regarding the Geopark, especially regarding the potential for tourism, accommodation, leisure, crafts,
\end{abstract}


and local cuisine. Entrepreneurs, artisans, people involved in tourism in the region, as well as residents and/or workers from the nine municipalities that make up the Quarta Colônia, were invited to take part in the research. Participants were provided with a link that gave direct access to an electronic questionnaire created on the Google Forms virtual platform. There was a prevalence of public servants; majority with knowledge about Geoproduct; as for the existence of guidance and tourist information, most answered not to know; there are no coherent tourist nameplates to serve tourists; there is public transport available; the presence of crafts inspired by the local landscape; food services with an emphasis on regional cuisine; rural and urban accommodation available; several leisure proposals. With this work, it became even more evident how much the region of the Fourth Colony of Italian immigration is prepared to become a Geopark.

Keywords: Geopark; Geoproduct; Regional gastronomy.

\section{Resumen}

El geoparque se puede definir como una forma de protección y promoción del patrimonio geológico y el desarrollo local sostenible. Este trabajo tuvo como objetivo hacer un diagnóstico del conocimiento de los principales actores sociales involucrados en el proyecto de Geoparque de la Quarta Colônia Aspirante UNESCO, identificando aspectos relacionados con su perfil, sus expectativas con respecto al Geoparque, especialmente en lo que se refiere al potencial turístico, hotelero, de ocio, artesanía y gastronomía local. Se invitó a participar en la investigación a empresarios, artesanos, personas vinculadas al turismo en la región, así como a residentes y/o trabajadores de los nueve municipios que integran la Quarta Colônia. A los participantes se les proporcionó un enlace que les dio acceso directo a un cuestionario electrónico creado en la plataforma virtual Google Forms. Hubo un predominio de servidores públicos; mayoría con conocimientos sobre Geoproducto; en cuanto a la existencia de orientación e información turística, la mayoría respondió no tener conocimientos; no hay placas turísticas coherentes para atender a los turistas; hay transporte público disponible; presencia de artesanías inspiradas en el paisaje local; servicios de alimentación con énfasis en la cocina regional; alojamiento rural y urbano disponible; varias propuestas de ocio. Con este trabajo, se hizo aún más evidente cuánto está preparada la región de la Quarta Colônia de inmigración italiana para convertirse en un Geoparque.

Palabras clave: Geoparque; Geoproducto; Gastronomía regional.

\section{Introdução}

Geoparque pode ser definido como uma forma de proteção e promoção do patrimônio geológico e do desenvolvimento sustentável local, em territórios que possuam uma geologia de valor destacado. Foi em 1991, na França, que começou um movimento implícito de geoparque, com a "Declaração dos Direitos à Memória da Terra”, assinada por mais de trinta especialistas de diferentes nacionalidades, alegando ser chegada a hora de proteger o patrimônio natural registrados nas rochas e paisagens. A Organização das Nações Unidas para a Educação, a Ciência e a Cultura (UNESCO), como apoiadora dos geoparques, incentiva ainda mais os diversos países que visam aumentar o valor do patrimônio da Terra, suas paisagens e formações geológicas, vindo ao encontro do objetivo da Agenda 21, a Agenda da Ciência para Meio Ambiente e Desenvolvimento (Schobbenhaus \& Silva, 2012).

A UNESCO começou seu trabalho com os geoparques em 2001, denominando-os como áreas geográficas únicas e unificadas, onde locais e paisagens de importância geológica internacional são gerenciados com um conceito holístico de proteção, educação e desenvolvimento sustentável, atendendo a oito dos Objetivos de Desenvolvimento Sustentável da Agenda 2030: Acabar com a pobreza em todas as suas formas em todos os lugares; Garantir uma educação de qualidade inclusiva e equitativa e promover oportunidades de aprendizagem ao longo da vida para todos; Alcançar a igualdade de gênero e empoderar todas as mulheres e meninas; Promover o crescimento econômico sustentado, inclusivo e sustentável, emprego pleno e produtivo e trabalho decente para todos; Tornar as cidades e assentamentos humanos inclusivos, seguros, resilientes e sustentáveis; Garantir padrões de consumo e produção sustentáveis; Tomar medidas urgentes para combater as mudanças climáticas e seus impactos; Fortalecer os meios de implementação e revitalizar a parceria global para o desenvolvimento sustentável (UNESCO, 2021).

Em 2021 chegou-se a 169 geoparques globais em quarenta e quatro países, sendo que no Brasil o único existente até então é o Araripe, localizado na Bacia do Araripe, estendendo-se ao sul do estado do Ceará, noroeste de Pernambuco e leste do 
Piauí (UNESCO, 2021). No entanto, em 2006, foi criado o Projeto Geoparques do Serviço Geológico do Brasil (CPRM), com propósito de identificar, levantar, descrever, diagnosticar e divulgar localidades com potencial para geoparques, visto que o país tem vasta extensão territorial com rica geodiversidade, aliada a sítios geológicos de importância ecológica, arqueológica, histórica e cultural (Schobbenhaus \& Silva, 2012).

Nesse contexto, surge a Quarta Colônia, como Geoparque Aspirante UNESCO, localizada na mesorregião CentroOriental Rio-Grandense. A Quarta Colônia Imperial, foi povoada por imigrantes oriundos de várias regiões da Itália, os quais receberam terras, assim como as três primeiras colônias italianas, que deram origem a Caxias do Sul, Bento Gonçalves e Garibaldi. Recebeu esse nome em função de ser a quarta colônia imperial criada no Rio Grande do Sul, porém, composta por nove municípios: Agudo, Dona Francisca, Faxinal do Soturno, Ivorá, Nova Palma, Pinhal Grande, Restinga Seca, São João do Polêsine e Silveira Martins (Loro \& Coelho, 2010), conforme mostra a Figura 1. A população estimada em 2020 de toda a Quarta Colônia foi de 45.422 pessoas, conforme dados do Instituto Brasileiro de Geografia e Estatística (IBGE, 2021), menor do que os dados apresentados por Mello e Froehlich (2019) referente a pesquisa do IBGE feita em 2014, em que se aproximava a 60 mil habitantes.

Figura 1- Mapa da localização do projeto Geoparque Quarta Colônia dentro do estado do Rio Grande do Sul.

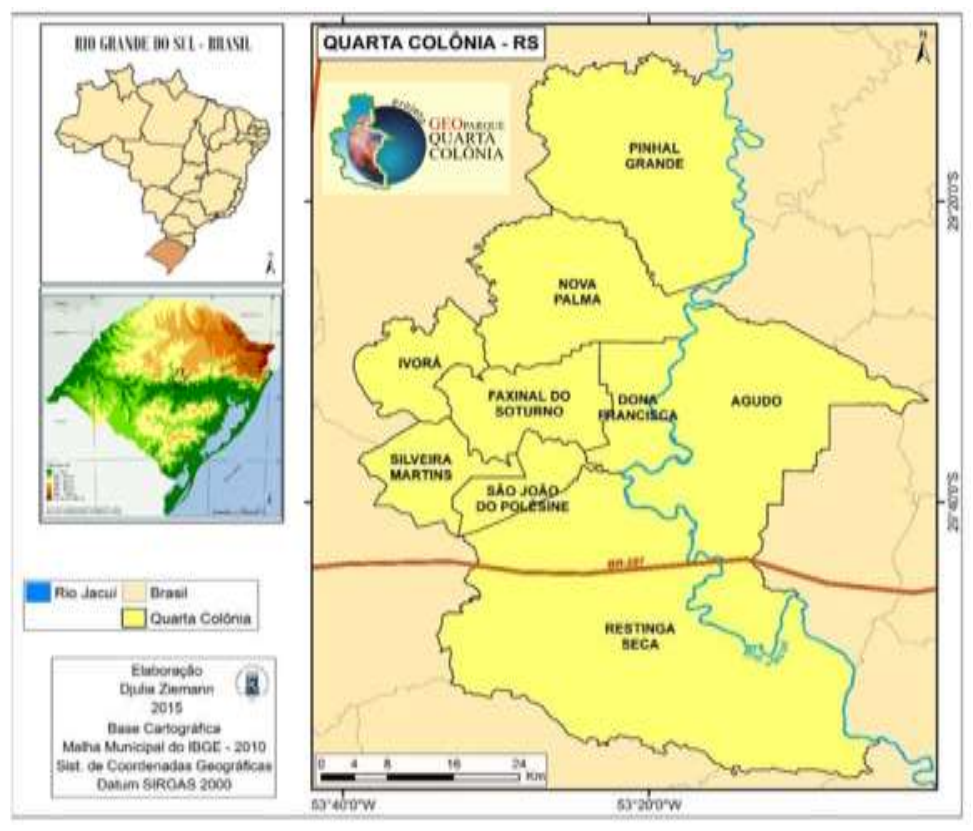

Fonte: Loro \& Coelho (2010).

No entanto, os primeiros imigrantes europeus a chegarem no atual território da Quarta Colônia, vieram em 1855 da Alemanha, mais precisamente da Pomerânia, instalando-se em Cerro Chato (atualmente município de Agudo), usufruindo das terras férteis da várzea do Jacuí para o cultivo de batata, feijão, milho, trigo, centeio, fumo e arroz. Foi em meados de 1877 que chegaram os primeiros imigrantes italianos abrindo picadas em meio a mata, construindo casas com arquitetura diversa, semelhante a dos alemães, criando lavouras, trabalhando a madeira, introduzindo uma nova cultura gastronômica, linguística e artística na região. Tanto imigrantes alemães quanto italianos, muito mais do que conflitos, agregaram uma maior diversidade entre os povos, os quais passaram a trabalhar de forma colaborativa, seja na organização das festas religiosas, ou nos mutirões de construção, plantio e colheita. Contribuindo ainda mais para essa diversidade, concomitantemente a chegada dos italianos 
também em outros pontos deste mesmo território, quilombos de escravos libertos iam fixando raízes e da mesma forma construindo novas e ricas identidades culturais (Figueiró, 2021).

Toda essa diversidade cultural contribuiu para a proposta de criação do Geoparque Quarta Colônia, que Segundo Godoy e colaboradores (2012), se deve ao fato da região ter uma rica fauna e flora fossilífera, com destaque para os fósseis do período Triássico, possibilitando maior conhecimento da origem dos dinossauros, dos mamíferos e da evolução das coníferas; além das características geormorfológicas do território, sendo uma área de transição entre a Depressão Periférica e o Plananto da Serra Geral, com contraste entre uma zona mais rebaixada e com relevo suave e outra mais elevada e com relevo mais acentuado. Ainda, os mesmos autores referenciam que além dos sítios geológicos e paleontológicos, merece detaque a infraestrutura para o turismo, a história e cultura arraigada dessa região e o engajamento das comunidades locais, consolidada pelo Consórcio de Desenvolvimento Sustentável da Quarta Colônia (CONDESUS), o qual teve início nos anos noventa com o Projeto Prodesus e se concretizou em 1995 como CONDESUS.

Em 2008 o CONDESUS deu início à elaboração da proposta de Geoparque, com o inventário geopatrimonial realizado pelo Serviço Geológico do Brasil (CPRM), já em 2015 esse inventário foi reavaliado e ampliado, com a revisão inicial dos vinte geossítios anteriormente inventariados pela equipe técnica da CPRM, onde alcançou-se um saldo positivo para o aproveitamento geoturístico em vinte e quatro sítios (Ziemann \& Figueiró, 2017a).

Assim, Ziemann e Figueiró (2017b), enfatizam que os geoparques vão além da proteção geopatrimonial, contribuindo inclusive com o desenvolvimento local da comunidade inserida. Ressaltam por exemplo, a importância de um geoturismo bem planejado, em consonância e respeito a preservação geopatrimonial, favorecendo mutuamente o desenvolvimento local de áreas com grande geodiversidade, como a região da Quarta Colônia.

Vindo ao encontro disso, a comunidade é incentivada a produzir e divulgar seus Geoprodutos, ou seja, produtos com identidade local, elaborados dentro de um Geoparque, podendo ser artesanal, semi industrializado e industrializado; para consumo humano ou souvenir, contribuindo para o desenvolvimento das capacidades locais e permitindo dinamizar as pequenas economias (Projeto Geoparque Quarta Colônia, 2019-2020).

Em se tratando de turismo, fator que merece destaque é a identidade étnica da região trazida pelos imigrantes italianos, traduzida na herança cultural ainda preservada e refletida através da religiosidade, do modo de falar, da arquitetura, das formas de lazer e principalmente das diversas festividades que compõem o calendário anual de cada município. As festas, principalmente católicas, buscam preservar a religiosidade, a cultura, a mesa farta e a confraternização, aflorando o interesse pelo turismo religioso, cultural, gastronômico e ambiental (Loro \& Coelho, 2010).

Santos, Ceretta e Ziemann (2015) percebem a gastronomia como um produto turístico, visto que o visitante normalmente busca conhecer aspectos da culinária local como forma de satisfazer seu paladar e de se aproximar da comunidade local, conhecendo seus pratos típicos, formas de preparo e distribuição peculiares, como mais uma manifestação cultural e simbólica de identidade de um povo, evidenciando-se assim, a gastronomia, como um insumo fundamental ao fomento da atividade turística.

Também o artesanato da Quarta Colônia, mesmo tendo seu papel subordinado à gastronomia nas mídias sociais, merece destaque por ser um importante elemento na composição da imagem identitária coletiva do território. Nessa conjuntura, o CONDESUS já promoveu diversos projetos, dentre eles a criação de cartões postais retratando elementos histórico-culturais da Quarta Colônia, folders de divulgação turística que ressaltaram diferentes aspectos do patrimônio existente no território, oficinas de criação de produtos que enfatizaram técnicas e temas locais, e o Caderno Quarta Colônia publicado semanalmente entre agosto de 2006 e novembro de 2011, o qual destacava atrativos turísticos do território, tanto seu patrimônio material, representado pela natureza e edificações históricas, quanto o patrimônio imaterial, como as tradições locais, práticas religiosas, especificidades gastronômicas e saberes artesanais (Mello \& Froehlich, 2019). 
Com isso, esse trabalho se propôs fazer um diagnóstico acerca do conhecimento dos principais atores sociais envolvidos no projeto Geoparque da Quarta Colônia Aspirante UNESCO, identificando aspectos referentes a seu perfil, suas expectativas quanto ao geoparque, principalmente quanto ao potencial turístico, de hospedagem, lazer, artesanato e gastronomia local.

\section{Metodologia}

O presente artigo tratou-se de um estudo transversal, descritivo e quantitativo; além de qualitativo, que segundo Gil (1996) se refere a compreensão de processos de forma complexa e contextualizada, realizado no período de maio a agosto de 2021, referente ao projeto Geoparque Quarta Colônia Aspirante UNESCO, com autorização do Consórcio de Desenvolvimento Sustentável da Quarta Colônia (CONDESUS), além do apoio da Universidade Federal de Santa Maria e Prefeituras Municipais, órgãos de Vigilância Sanitária e Serviço de Inspeção Municipal dos municípios e Empresa de Assistência Técnica e Extensão Rural (EMATER/RS) dos nove municípios.

Foram convidados a fazer parte da pesquisa empreendedores de diversas atividades, artesãos e pessoas envolvidas com o turismo na região, além de residentes e/ou trabalhadores, maiores de dezoito anos, dos nove municípios integrantes da Quarta Colônia. Inicialmente, foi organizado pela Comissão de Negócios e Renda, um grupo na multiplataforma de mensagens instantâneas (WhatsApp) sob a técnica de amostragem não probabilística "bola de neve", que parte do pressuposto de que pessoas indicadas (informantes) enviem a seus contatos pessoais a mensagem convite de participação, ou seja, utiliza cadeias de referência, uma espécie de rede (Vinuto, 2014), aproximando os empresários dos nove municípios dos mais diversos ramos de atividades. O convite para o preenchimento do formulário foi divulgado através da plataforma (WhatsApp) com a colaboração de diversos órgãos envolvidos, como: o Comitê Gestor Geoparque Quarta Colônia Aspirante UNESCO (com representantes da Universidade Federal de Santa Maria; CONDESUS; Comissão de Turismo e Meio Ambiente; Comissão de Educação, Cultura e Comunicação; Comissão de Negócios e Renda), além da EMATER, Prefeituras, Secretarias do Turismo, do Meio Ambiente e da Educação.

Às pessoas pertencentes ao grupo formado na multiplataforma de mensagens, após consentirem sua participação, era disponibilizado um link que dava acesso direto a um questionário eletrônico elaborado na plataforma virtual Google Forms, com perguntas objetivas e dissertativas a respeito do local de moradia e de trabalho; ocupação; conhecimento sobre geoproduto, agenciamento turístico, serviço de alimentação com ênfase na gastronomia, existência de agroindústrias, transporte coletivo público, oferta de souvenirs inspirados na paisagem e/ou cultura local, hospedagem integrada a paisagem e/ou localizada no espaço urbano, oferta de passeios e demais atividades de lazer e entretenimento.

Os dados foram tabulados no programa Microsoft Excel e analisados através de tabelas simples e cruzadas com auxílio do software Statistical Analysis System versão 9.2. Também foi utilizado o programa Mentimeter (https://www.mentimeter.com) para confecção das nuvens de palavras (Words Cloud), ou seja, gráficos digitais que mostram o grau de frequência de palavras citadas.

\section{Resultados e Discussão}

Durante o período em que o questionário esteve disponível, 123 pessoas acessaram e responderam às questões propostas, destas 106 residentes em um dos nove municípios da Quarta Colônia, sendo que 17 respondentes marcaram outra localidade, provavelmente, sejam pessoas que trabalham em um dos municípios, porém residem em cidade próxima, não pertencente a região em questão. Ainda, quanto ao local de trabalho, além dos que residem fora da Quarta Colônia há também os que moram em uma das cidades, mas trabalham em outra, porém a maioria reside e trabalha no mesmo município. Houveram casos de participantes moradores (munícipes) da Quarta Colônia que não trabalham ou não atuam na região (Tabela 1). 
Tabela 1- Local de moradia e trabalho dos participantes da pesquisa “Diagnóstico de Negócios na Quarta Colônia - Programa Geoparque QC", 2021.

\begin{tabular}{lll}
\hline Cidade & Residência & Trabalho \\
\hline Agudo & 3 & 7 \\
Dona Francisca & 17 & 15 \\
Faxinal & 14 & 13 \\
Ivorá & 5 & 6 \\
Não trabalham na Quarta Colônia & & 14 \\
Nova Palma & 4 & 3 \\
Outra & 17 & \\
Pinhal Grande & 2 & 3 \\
Restinga Seca & 8 & 8 \\
São João do Polêsine & 21 & 21 \\
Silveira Martins & 32 & 33 \\
\hline TOTAL & 123 & 123 \\
\hline
\end{tabular}

Fonte: Autores (2021).

Com relação ao setor de atuação dos respondentes, percebeu-se as mais diversas áreas, com prevalência de servidores públicos, como pode ser visto no Gráfico 1.

Gráfico 1. Áreas de atuação dos participantes da pesquisa "Diagnóstico de Negócios na Quarta Colônia - Programa Geoparque QC", 2021.

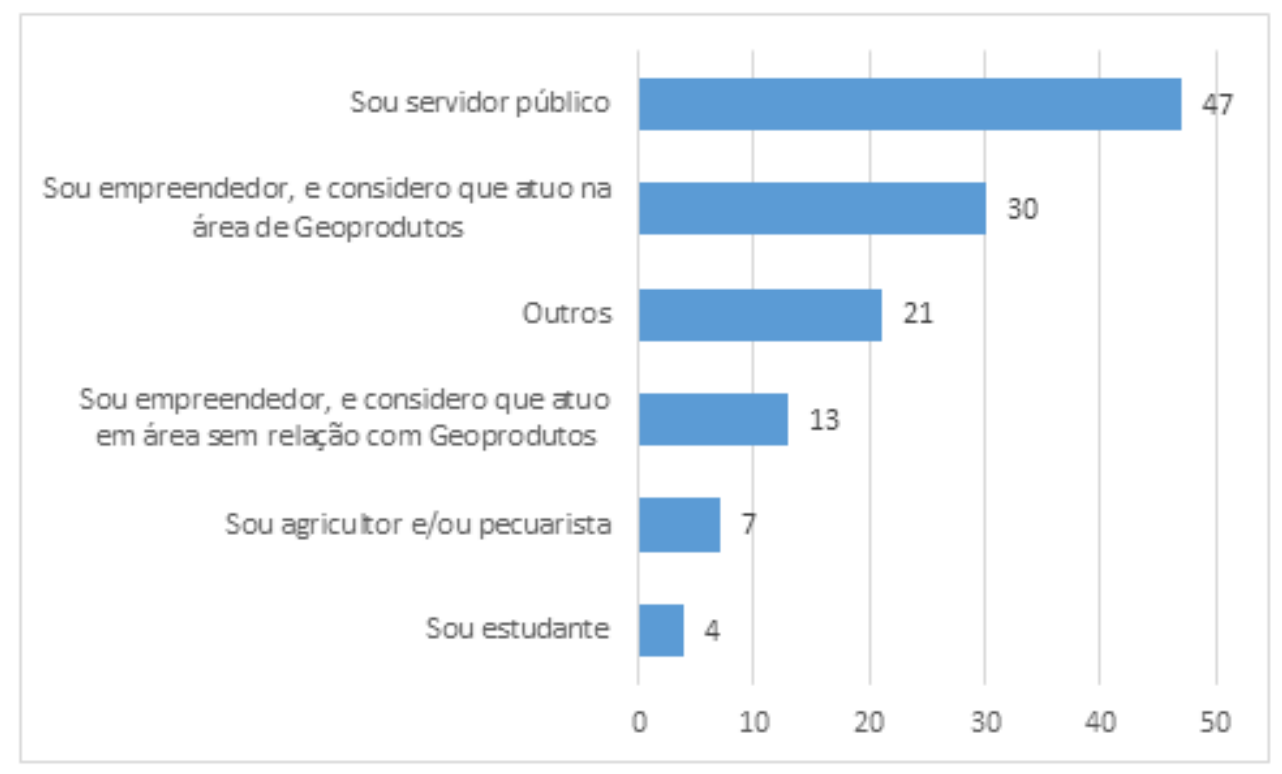

Fonte: Autores (2021).

Quando questionados em relação ao conhecimento sobre Geoproduto, a maioria relatou ter conhecimento (Gráfico 2), provavelmente pela ampla divulgação acerca do assunto, haja vista que foram várias reuniões com a Comissão de Negócios e Renda, na qual participam representantes do Comitê Gestor do Geoparque, Membros Natos, professores e técnicos administrativos 
da Universidade Federal de Santa Maria; CONDESUS; Comissão de Turismo e Meio Ambiente; Comissão de Educação, Cultura e Comunicação; além da EMATER, Prefeituras, Secretarias do Turismo, do Meio Ambiente e da Educação, reuniões essas que ocorreram em diferentes momentos em cada um dos nove municípios, inicialmente com a intenção de discutir em relação as demandas e particularidades de cada cidade.

Gráfico 2. Grau de conhecimento sobre Geoproduto por parte dos participantes da pesquisa "Diagnóstico de Negócios na Quarta Colônia - Programa Geoparque QC", 2021.

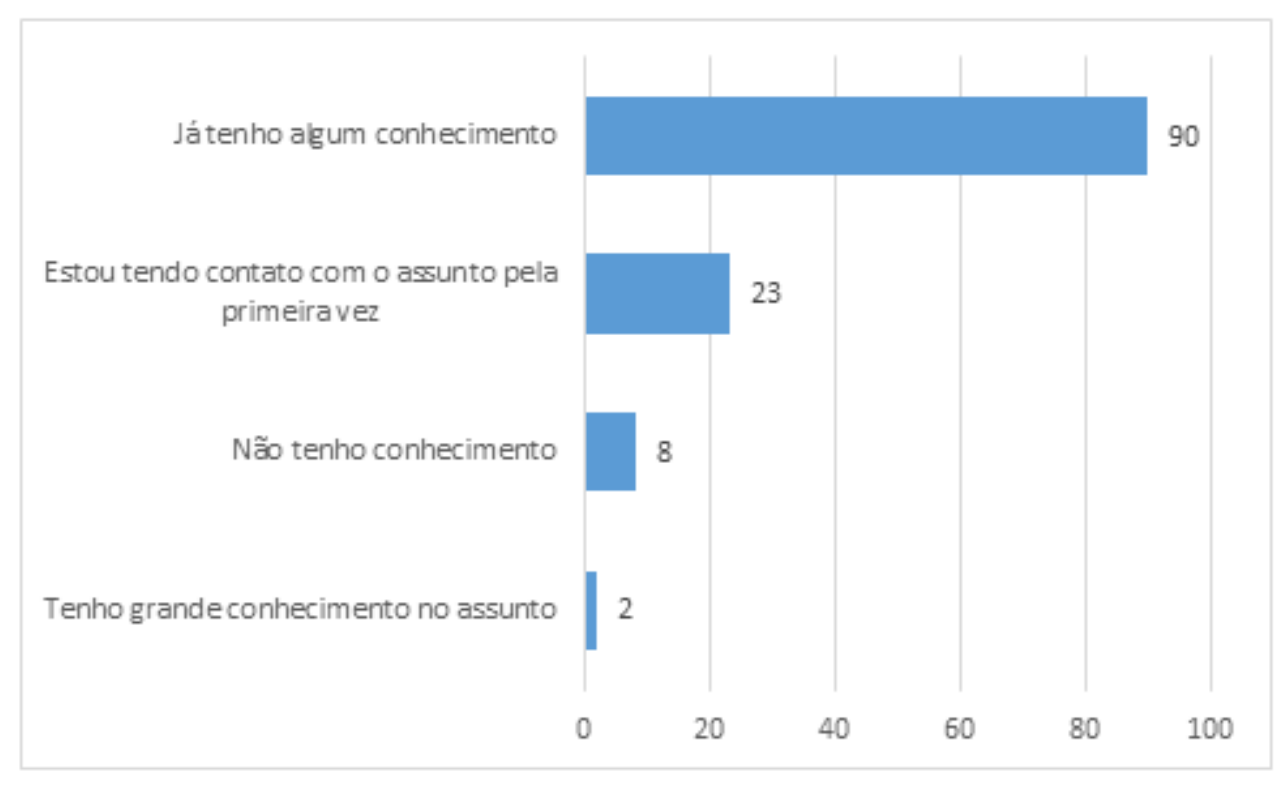

Fonte: Autores (2021).

Conforme Degrandi et al. (2018), Geoprodutos conceituam-se como produtos culturais e turísticos, gerados por meio de festas comunitárias, artesanato e culinária típica, favorecendo a valorização e divulgação do patrimônio territorial, além de auxiliar na geração de emprego e renda da comunidade envolvida. Os mesmos citam que a Quarta Colônia apresenta grande potencial em relação aos Geoprodutos, porém precisam ser melhor explorados, sugerindo para isso adaptações nos formatos, embalagens e rótulos de produtos alimentícios e artesanato relacionando-os a geodiversidade local, como por exemplo colocar pegadas de dinossauros, datadas do período Triássico, atribuídas a terópodes do icnogênero Eubrontes nas tradicionais cucas alemãs; também produzir as habituais bolachas de manteiga e palhas italianas no formato dos vertebrados fósseis, principalmente os dinossauros encontrados nos afloramentos da Quarta Colônia, sendo estes os primeiros a habitarem o planeta, datados do período Triássico.

Frente a essas sugestões, os participantes foram questionados se existe oferta de produtos identificados com rótulos e embalagens com identidade local, e o resultado foi bem favorável, visto que 78 (63\%) responderam que sim, 27 (22\%) relataram não ter conhecimento e apenas 18 (15\%) responderam que não, provavelmente esses valores estejam melhorando em decorrência das inúmeras reuniões em que são levantadas demandas ao mesmo tempo em que sugestões e orientações são repassadas sempre com o intuito de capacitar e tornar ativos todos os membros da comunidade que tenham interesse em tornar seu produto um Geoproduto.

De forma mais ampla foi perguntado se os serviços e empreendimentos locais estão preparados para receber o turista, de maneira em que o visitante, dirigindo-se ao comércio poderá ser informado sobre os pontos turísticos ou melhores locais para visitar, e como resultado a maioria colocou que ainda não (57\%), porém sugeriram alternativas para reverter esse 
resultado, através de capacitações na área de acolhimento ao turista, citando formações nas áreas de: hospitalidade, cordialidade, acolhimento, informações turísticas, conhecimento cultural, gerenciamento, língua estrangeira, organização dos serviços, estrutura adequada, paisagismo, gastronomia, hotelaria, guiamento turístico, desenvolvimento da agroindústria. Corroborando, Moreira (2014) expressa que as capacitações e reciclagens do conhecimento são fundamentais para preparar o profissional para contato com o público, devendo ele conhecer e compreender seu ambiente para melhor educar e orientar seus visitantes.

Lembrando que o turismo, pode ser considerado como uma maneira de impedir que os efeitos da globalização sobre o espaço regional da Quarta Colônia desconstruam a identidade do povo que ali habita, povo esse que carrega toda uma herança histórica italiana através da preservação dos códigos culturais frente aos novos arranjos espaciais, devido principalmente à forte ligação afetiva da comunidade, que através do turismo também pode alavancar sua renda (Manfio, 2012).

Moreira (2014) também compactua da ideia de que essas áreas protegidas devem preservar e conservar o patrimônio geológico para que as futuras gerações usufruam da mesma, além de educar o público em geral sobre temas relacionados a paisagens geológicas, prover subsídios para pesquidas em geociências, e, assegurar o desenvolvimento sustentável da região através do turismo.

Corroborando, um bom conceito para Geoturismo talvez seja o de Hose (2000), o qual descreve como a disponibilidade de serviços e meios interpretativos que promovam o valor e os benefícios sociais de locais com elementos geológicos e geomorfológicos, assegurando sua conservação, para bom proveito de turistas, estudantes e demais pessoas com interesse recreativo e de lazer.

Ainda, no que tange ao potencial turístico, os participantes foram questionados em relação a existência de serviço de agenciamento e guiamento turístico no município em que residem e/ou trabalham, além do serviço de informação turística prestado. Percebeu-se com os resultados, como pode ser visto na Tabela 2, que a maioria relata não ter conhecimento sobre existência de guiamento turístico, e da mesma forma grande parte refere não ter conhecimento sobre informação turística disponível aos turistas, vindo ao encontro dos relatos feitos durante as reuniões municipais, em que normalmente era identificada como demanda melhorar a divulgação de pontos turísticos, serviços e produtos.

Tabela 2 - Conhecimento dos participantes da pesquisa "Diagnóstico de Negócios na Quarta Colônia - Programa Geoparque QC” quanto à existência de guiamento e informações turísticas na Quarta Colônia, 2021.

\begin{tabular}{|c|c|c|c|c|}
\hline \multirow{3}{*}{ Guiamento turístico } & \multicolumn{3}{|c|}{ Informação turística } & \multirow[b]{2}{*}{ Total } \\
\hline & Não & $\begin{array}{c}\text { Não tenho } \\
\text { conhecimento }\end{array}$ & Sim & \\
\hline & $\mathrm{n}(\%)$ & $\mathrm{n}(\%)$ & $\mathrm{n}(\%)$ & $\mathrm{n}(\%)$ \\
\hline Não & $22(17,89)$ & $9(7,32)$ & $12(9,76)$ & $43(34,96)$ \\
\hline Não tenho conhecimento & $8(6,50)$ & $22(17,89)$ & $15(12,20)$ & $45(36,58)$ \\
\hline Sim & $8(6,50)$ & $12(9,76)$ & $15(12,20)$ & $35(28,46)$ \\
\hline Total & $38(30,89)$ & $43(34,96)$ & $42(34,15)$ & 123 \\
\hline
\end{tabular}

Fonte: Autores (2021).

Aos participantes que confirmaram a existência de serviço de agenciamento e guiamento turístico foi solicitado, conforme mostrado na Figura 2, que citassem os referidos serviços. Já em relação às informações turísticas, os que relataram ocorrer, ressaltaram que funciona de segunda-feira a sexta-feira, sendo realizada pela administração pública municipal, além de informações 
colhidas em hotéis, museus, postos de gasolina, pressupondo que de forma efetiva não existem locais com esse propósito, vindo novamente ao encontro das demandas levantadas pelos municípios.

Figura 2. Serviços de agenciamento e guiamento turístico da Quarta Colônia citados pelos respondentes da pesquisa "Diagnóstico de Negócios na Quarta Colônia - Programa Geoparque QC", 2021. Observação: Quando foram citados nomes e não agências o serviço foi exposto como particular.

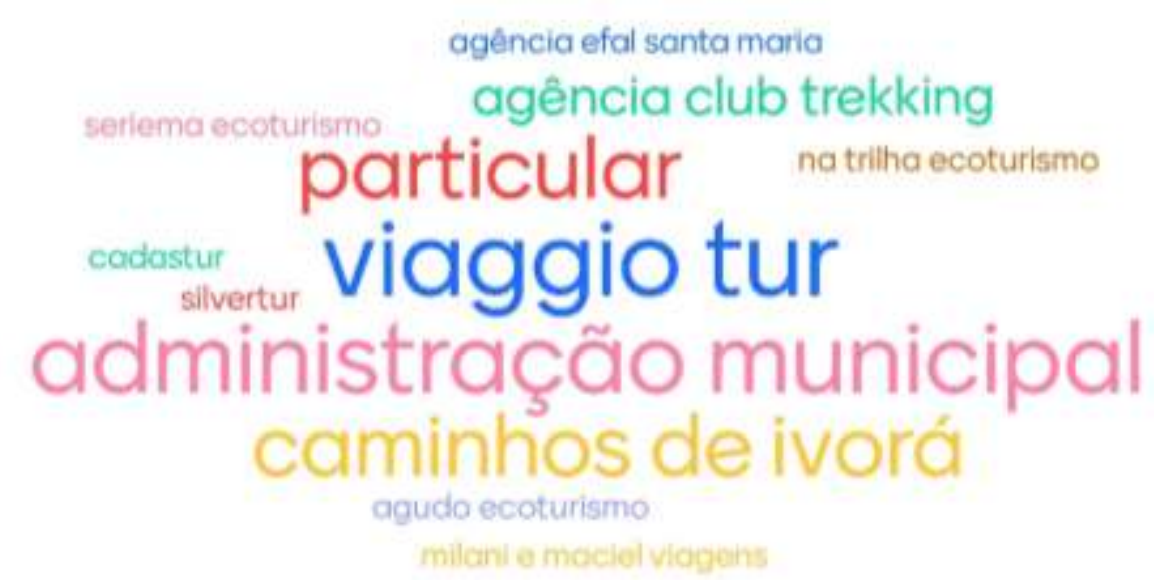

Fonte: Autores (2021).

Provavelmente, o que também poderia levar a um melhor direcionamento aos turistas seriam placas de identificações turísticas, porém, quando os respondentes da pesquisa foram questionados se consideravam que as placas de seu município estavam coerentes para auxiliar os visitantes, 64 (52\%) relataram que não, enquanto 46 (37\%) que sim e 13 (11\%) não tinham conhecimento.

Importante também para o turismo é identificar se existe transporte coletivo disponível, sendo que 35 (29\%) respondeu não haver; 9 (7\%) não ter conhecimento; 57 (46\%) relatou que existe transporte de acesso intermunicipal até o município, através de roteiro de linha de ônibus; e, 22 (18\%) que existe transporte interno através da oferta de fretamento, como taxi, micro-ônibus, ônibus.

Além dos meios de transporte, divulgação dos atrativos turísticos, gastronomia local, também o artesanato merece destaque especial. A possibilidade de se transpor a realidade local em um produto turístico, deve ser explorada, haja vista que além de ser um souvenir, o geoproduto estará valorizando a geodiversidade local, o saber fazer da comunidade (Degrandi et al., 2018).

Nesse contexto, quando questionados sobre haver a oferta de lembranças/souvenires inspirados na paisagem e/ou cultura local, a maioria respondeu que sim e, também, que os artesãos do seu município realizam divulgação dos seus produtos ao turista (Tabela 3). Porém, os mesmos foram instigados a propor ações para maior divulgação, onde citaram: redes sociais (facebook, whatsApp, site da prefeitura), folder de cada município, jornais locais, panfletagem em diversos locais, banners, participação em feiras regionais e estaduais de artesanato, espaços específicos para exposição dos produtos, feiras livres, programas de rádio e televisão, promoção de eventos, amostras e festivais periódicos. 
Tabela 3 - Conhecimento dos participantes da pesquisa "Diagnóstico de Negócios na Quarta Colônia - Programa Geoparque QC" quanto a existência e divulgação pelos artesãos de lembranças/souvenires inspirados na paisagem e/ou cultura local, 2021.

\begin{tabular}{|c|c|c|c|c|}
\hline \multirow{3}{*}{ Lembranças } & \multicolumn{3}{|c|}{ Divulgação } & \multirow[b]{2}{*}{ Total } \\
\hline & Não & $\begin{array}{c}\text { Não tenho } \\
\text { conhecimento }\end{array}$ & Sim & \\
\hline & $\mathrm{n}(\%)$ & $\mathrm{n}(\%)$ & $\mathrm{n}(\%)$ & $\mathrm{n}(\%)$ \\
\hline Não & $20(16,26)$ & $8(6,50)$ & $4(3,25)$ & $32(26,02)$ \\
\hline Não tenho conhecimento & $4(3,25)$ & $28(22,76)$ & $7(5,69)$ & $39(31,71)$ \\
\hline Sim & $12(9,76)$ & $5(4,07)$ & $35(28,46)$ & $52(42,27)$ \\
\hline Total & $36(29,27)$ & $41(33,33)$ & $46(37,40)$ & 123 \\
\hline
\end{tabular}

Fonte: Autores (2021).

Quanto à hospedagem, foi perguntado aos participantes da pesquisa se no município da Quarta Colônia em que residem e/ou trabalham existe oferta de hospedagem que esteja integrada a paisagem, como pousada, hotel, hostel, hospedagem familiar, camping, dentre outras. A grande maioria respondeu que existe (77=63\%), 26 (21\%) responderam não haver e 20 (16\%) relataram não ter conhecimento, já quando questionados sobre existir outros tipos de oferta de hospedagem localizada no espaço urbano (centro da cidade), $82 \%$ relataram haver. Após foram incentivados a contribuir, citando as hospedagens existentes, tanto no meio rural quanto urbano. O Quadro 1 mostra os principais empreendimentos citados, tanto no meio rural quanto urbano.

Quadro 1. Conhecimento dos participantes da pesquisa "Diagnóstico de Negócios na Quarta Colônia - Programa Geoparque QC" quanto à hospedagem no meio rural e no meio urbano, 2021.

\begin{tabular}{|l|l|}
\hline \multicolumn{1}{|c|}{ Meio rural } & \multicolumn{1}{|c|}{ Meio urbano } \\
\hline Hotel Recanto Business & Hotel Pinton \\
Hotel Capo Zorial & Hotel Bel Recanto \\
Pousada Recanto Maestro & Hotel Ouro Preto \\
Pousada Nonno Arlindo & Hotel São João \\
Pousada Vêneto & Hotel Germânico \\
Pousada Jacuí & Hotel Zanon \\
Casa de Retiros Nossa Senhora de Lourdes & Hotel Havai \\
Sabores da Cabana & Hotel da Gema \\
Praia das Tunas & Termas Romanas \\
Balneário Municipal & Pousada Monte Santo \\
Hospedagem do Vale & Residencial Bella Locanda \\
Cabanas do Dutra & \\
Cabanas Paraíso & \\
Cabanas Trilhas de Ivorá & \\
Camping Balneário Drews & \\
Chácara Santa Eulália & \\
\hline
\end{tabular}


Gomes, Barros e Santos (2020) relacionam o turismo rural com a prática do geoturismo, uma vez que ambos apresentam características similares em se tratando do conceito holístico de conservação, turismo e educação, favorecendo o desenvolvimento regional. Os mesmos deixam claro que os geoparques são territórios que enfatizam além das feições geológicas, a junção de elementos turísticos, científicos, culturais e arqueológicos que se somam e resultam em um atrativo turístico singularizado.

Outro aspecto importante que serve de atrativo para turistas diz respeito ao lazer e entretenimento, assim os participantes foram questionados da existência da oferta de passeios ou propostas de atividades de lazer, como esportes de aventura, trilhas incorporadas a natureza, por exemplo. Como resultado, 46 (37\%) relataram haver essas propostas, 43 (35\%) não haver e 34 (28\%) não ter conhecimento acerca do assunto.

E por fim, algo que também merece destaque, é a gastronomia regional, vista como algo que conquista o turista e faz com que o mesmo queira retornar ao local. Assim, foi questionado aos participantes da pesquisa se no município em que residem e/ou trabalham existe serviço de alimentação com ênfase na gastronomia local e em caso afirmativo se esses locais estão capacitados para receber o turista, conforme pode ser visto na Tabela 5.

Tabela 5 - Conhecimento dos participantes da pesquisa "Diagnóstico de Negócios na Quarta Colônia - Programa Geoparque QC" quanto a existência de serviços de alimentação (SA) com ênfase na gastronomia regional e preparo para receber turistas, 2021.

\begin{tabular}{lcccc}
\hline \multirow{2}{*}{$\begin{array}{l}\text { SA com gastronomia } \\
\text { regional }\end{array}$} & Não & $\begin{array}{c}\text { Não tenho } \\
\text { conhecimento }\end{array}$ & \multirow{2}{*}{ Sim } & \\
\cline { 2 - 4 } & $\mathrm{n}(\%)$ & $\mathrm{n}(\%)$ & $\mathrm{n}(\%)$ & $\mathrm{n}(\%)$ \\
\cline { 2 - 4 } & $16(13,01)$ & $3(2,44)$ & $4(3,25)$ & $23(18,70)$ \\
\hline Não & $1(0,81)$ & $5(4,07)$ & $8(6,50)$ & $14(11,38)$ \\
Não tenho conhecimento & $8(6,50)$ & $10(11,63)$ & $68(55,28)$ & $86(69,92)$ \\
Sim & $25(20,32)$ & $18(14,63)$ & $80(65,04)$ & 123 \\
\hline \multicolumn{1}{c}{ Total } & & & \\
\hline
\end{tabular}

Fonte: Autores (2021).

Constata-se que a maioria considera que os serviços de alimentação cultivam a tradição em suas preparações e estão capacitados para receber os turistas. Importante colocação é feita por Marcuzzo (2021), a qual referência que o turista vai a Quarta Colônia com a certeza de que irá saborear a típica gastronomia da região e usufruir da atmosfera de música, alegria e religiosidade, além de encontrar belas encostas verdejantes e heranças sobre nossa pré-história.

Corroborando, foram questionados acerca do que pensam ser importante para os serviços de alimentação em relação as demandas quanto ao atendimento ao turista (Figura 3). 
Figura 3 - Demandas dos serviços de alimentação no atendimento ao turista, 2021. (www.mentimeter.com)

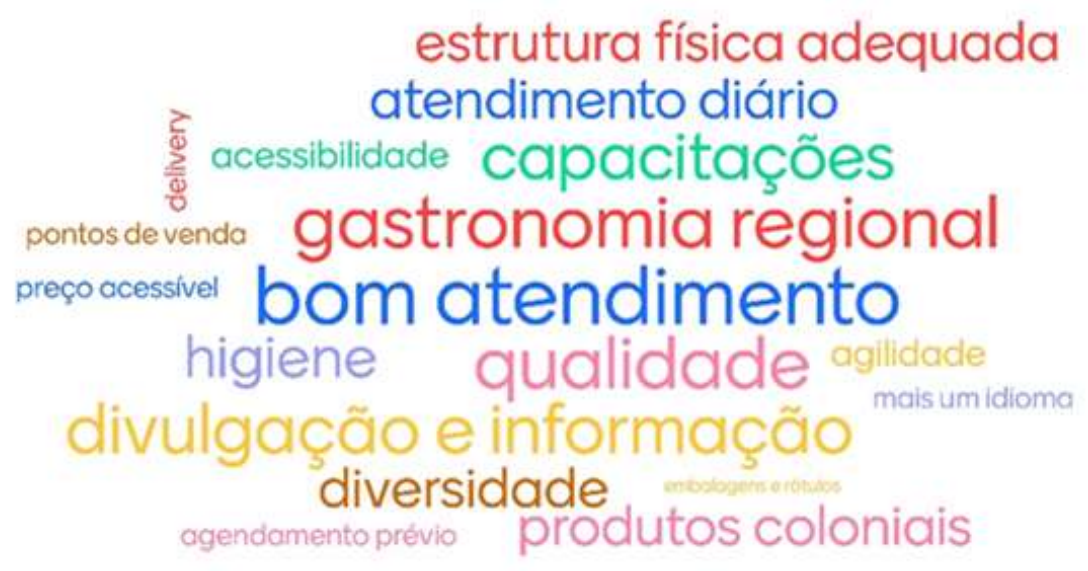

Fonte: Autores (2021).

Ainda, os participantes da pesquisa foram questionados quanto a existência de agroindústrias na região da Quarta Colônia, onde $112(91 \%)$ responderam haver, 9 (7\%) não ter conhecimento e 2 não existir (2\%).

E, por fim, os respondentes tiveram a oportunidade de opinar acerca de demandas de cursos voltados aos serviços turísticos de forma geral, em relação a alimentação, hospedagem, agenciamento, guiamento, artesanato e agroindústria. Mas, pela importância que as formações têm e pelo interesse em proporcionar de forma efetiva cursos para aprimoramento em diversos ramos, os participantes foram ainda mais instigados, sugerindo cursos específicos para auxiliar na melhoria de seu próprio negócio/serviço, conforme mostrado no Quadro 2. 
Quadro 2 - Demanda por cursos voltados aos serviços turísticos e cursos específicos sugeridos pelos participantes da pesquisa "Diagnóstico de Negócios na Quarta Colônia - Programa Geoparque QC", 2021.

\begin{tabular}{|l|l|}
\hline \multicolumn{1}{|c|}{ Demanda por cursos voltados aos } & \multicolumn{1}{c|}{ Sugestões de cursos específicos } \\
\hline Guiamento turístico & \\
Agencicos & História patrimonial \\
Gastronomia & Gerenciamento \\
Atendimento ao público & Fluxo de caixa \\
Hospedagem & Boas práticas de fabricação \\
Artesanato & Condutores locais \\
Gerenciamento & Corte e costura \\
Agroindústria & Gestão de pessoas \\
Empreendedorismo & Turismo rural \\
Boas práticas em Serviços de Alimentação & Mídias digitais \\
Recepção & Cooperativismo \\
Idiomas & Guiamento turístico \\
Custos & Atendimento ao público \\
Garçom & Culinária \\
Camareira & Paisagismo \\
Paisagismo & Comunicação \\
& Hotelaria \\
& Marketing \\
& Informática \\
& Destilados \\
& Açougue \\
& Vendas online \\
& Idiomas \\
& Agroindústria \\
& Artesanato \\
& Garçom \\
& Frentistas \\
& Massas \\
\hline
\end{tabular}

Fonte: Autores (2021).

Referente as demandas, sejam gerais ou específicas, percebe-se claramente o consenso em haver capacitações na área de melhor atendimento ao público, que segundo Moreira (2014), essa receptividade bem conduzida tem o poder de criar um vínculo entre o turista e os envolvidos no empreendimento, assim como cursos voltados a gastronomia típica, tem esse mesmo poder de atrair e fazer com que o visitante tenha vontade de retornar ao local, sendo necessário uma boa divulgação através de agenciamento e guiamento turístico. Ainda, para Padoin, Figueiró e Cruz (2021) a formação de lideranças nos campos do patrimônio, com base na história, é uma necessidade fundamental para qualquer sociedade, buscando tratar a educação patrimonial como um processo 
permanente de aproximação entre a comunidade do território e suas heranças, de tal forma que este processo de conhecimento, apropriação e valorização patrimonial leve a um progressivo enriquecimento individual e coletivo da comunidade.

Quando pesquisado a respeito de outro Aspirante a Geoparque, envolvendo Caçapava do Sul e seus vizinhos, Borba (2017) concluiu a necessidade de seguir acontecendo iniciativas de geoeducação, bem como uma progressiva preparação da região para o geoturismo, por meio de capacitações de artesãos, produtores rurais e estabelecimentos voltados ao turismo e a hotelaria.

Na perspectiva de geoeducação, Figueiró et al. (2009) ressaltaram a importância de estratégias pedagógicas com materiais geoeducativos que servirão como ferramentas de disseminação do conhecimento científico, como os já elaborados: jogo de Role Playing Game (RPG), caderno didático do Geoparque Quarta Colônia e maquete em grande formato do território, com a intenção de aproximar os educandos e os visitantes da realidade do território do Geoparque por meio de uma aprendizagem ativa, servindo esses materiais como ferramentas de conscientização e valorização do patrimônio, além de despertar o interesse do uso dos geossítios como atração geoturística.

\section{Conclusão}

Com esse trabalho ficou ainda mais evidente o quanto a região da Quarta Colônia de imigração italiana está preparada para se tornar um Geoparque, visto que os principais atores envolvidos, ou seja, moradores dos nove municípios, juntamente com CONDESUS e integrantes da Universidade Federal de Santa Maria, estão empenhados e mobilizados em busca desse reconhecimento.

Sabe-se que a junção de vários fatores que levarão a essa conquista, dentre eles a rica geologia, fauna e flora fossilífera, características geormorfológicas do território, sítios geológicos e paleontológicos, infraestrutura para o turismo, gastronomia típica, artesanato com ênfase na cultura local, lazer e entretenimento integrado a lindas paisagens, muita história e cultura patrimonial. Nesse sentido, os participantes da pesquisa evidenciaram muitas potencialidades e em relação aos pontos que foram vistos talvez como fragilidades temporárias, os mesmos sugeriram propostas a serem sanadas em curto espaço de tempo, como as capacitações em algumas áreas, com intuito de bem atender e satisfazer aos anseios dos turistas.

Com o território sendo reconhecido como Geoparque, o desenvolvimento local será um processo endógeno de mudanças, que, certamente será iniciado a partir do dinamismo econômico, melhorando a qualidade de vida dos munícipes dos nove municípios que compõem a Quarta Colônia de Imigração Italiana e, para ser consistente e sustentável, é imprescindível a mobilização dos vários atores envolvidos neste projeto na descoberta das potencialidades locais, nas oportunidades sociais e sua viabilidade. O desenvolvimento da economia local deve assegurar a conservação dos recursos naturais locais, suas capacidades e potencialidades próprias.

Como sugestão para prosseguimento da pesquisa faz-se importante identificar, novamente com atores sociais envolvidos no processo, critérios para utilização dos selos: geoproduto, parceiro e amigo do Geoparque Quarta Colônia.

\section{Referências}

Borba, W. A. (2017). Um geopark na região de Caçapava do Sul (RS, Brasil): uma discussão sobre viabilidade e abrangência territorial. Geographia Meridionalis, 3(1), 104-133.

Degrandi, S.; Ziemann, D.; Cechin, D.; Figueiró, A. (2018). Geoprodutos: estratégia para valorização e promoção da geodiversidade. XII SINAGEO paisagem e geodiversidade. https://www.sinageo.org.br/2018/trabalhos/5/5-424-2204.html

Figueiró, A. S., Motta. V., Brunhauser, T., Ventura, H., \& Cechin, D. (2019). A produção de materiais geoeducativos na proposta do Geoparque Quarta Colônia, RS. Physis Terrae, 1(2), 171-184.

Figueiró, A. S. Patrimônio natural e educação para a paisagem no geoparque Quarta Colônia: um território de descobertas. In: Padoin, Figueiró e Cruz (Org). (2021). Educação patrimonial em territórios geoparques: uma visão interdisciplinar na Quarta Colônia. Facos - UFSM, 180p..

Gil, A. C. (2002). Como elaborar projetos de pesquisa. (4a ed.). São Paulo: Atlas. 175p. 
Research, Society and Development, v. 10, n. 16, e165101623234, 2021

(CC BY 4.0) | ISSN 2525-3409 | DOI: http://dx.doi.org/10.33448/rsd-v10i16.23234

Godoy, M. M.; Binotto, R. B.; Silva, R. C. da., Zerfass, H. (2012). Geoparques/propostas: Quarta Colônia (RS). In: Schobbenhaus, C.; Silva, C. R. da (Org.). Geoparques do Brasil: propostas. Rio de Janeiro: CPRM, 417- 456.

Gomes, C. S. C. D.; Barros, C. L. P.; Santos, L, de A. (2020). Turismo rural e geoparques: um enlace para o fortalecimento do Seridó potiguar. Anais do XVII Seminário Anual da Associação Nacional de Pesquisa e Pós-Graduação em Turismo, 15p. https://www.anptur.org.br/anais/anais/sumario.php?versao=12

Hose, T. A. (2000). Geoturismo europeo. Interpretación geológica y promoción de la conservación geológica para turistas. In: Barretino, D; Winbledon, W.A.P; Gallego, E. (Orgs). Patrimonio geológico: conservatión y gestión. Madrid: Instituto Tecnológico Geominero de España, 137-159.

Instituto Brasileiro de Geografia e Estatística. (2010). Cidades. Recuperado de https://cidades.ibge.gov.br/

Loro, N. S.; Coelho, E. R. B. (2010). As festas religiosas e o turismo na Quarta Colônia Imperial de Imigração Italiana, RS: as razões dos frequentadores das festas. Disciplinarum Scientia, 6(1), 111-120.

Manfio, V. A. (2012). Quarta Colônia de imigração italiana: uma paisagem cultural na região central do Rio Grande do Sul. Geografia, ensino \& pesquisa, 16(2), 31-45.

Marcuzzo, S., B. (2021). Bicho do mato da colônia: somos todos mata atlântica. In: PADOIN, FIGUEIRÓ e CRUZ (Org), Educação patrimonial em territórios geoparques: uma visão interdisciplinar na Quarta Colônia. Facos - UFSM, 180p.

Mello, C. L.; Froehlich, J. M. (2019). Identidade territorial e visibilidade midiática: o artesanato no Caderno Quarta Colônia. Interações: Revista Internacional de Desenvolvimento Local, 20(3), 769-784.

Moreira, J. C. (2014). Geoturismo e interpretação ambiental. Ponta Grossa: UEPG, 157p.

Organização das Nações Unidas para a Educação, a Ciência e a Cultura. https://en.unesco.org/global-geoparks

Padoin, M. M., Figueiró, A., Cruz, J. A. S. (2021). Educação patrimonial em territórios geoparques: uma visão interdisciplinar na Quarta Colônia. Facos UFSM, 180p.

Projeto Geoparque Quarta Colônia. Relatório de Ações 2019/2020. Condesus, UFSM. https://www.ufsm.br/app/uploads/sites/346/2020/06/geoparque-quartacol\%C3\%B4nia_relatorio-2019.20-1.pdf

Santos, N. R. Z. dos.; Ceretta, C. C.; Ziemann, D. R. (2015). Cafés coloniais como referência cultural e atrativo turístico no município de Agudo-RS/Brasil. Geografia, Ensino \& Pesquisa, 19(1), 39-48.

Schobbenhaus, C.; Silva, C. R. da. (2012). Geoparques propostas do Brasil. Rio de Janeiro:CPRM, v.1, 748p.

Vinuto J. (2014). A amostragem em bola de neve na pesquisa qualitativa: um debate em aberto. Temáticas, Campinas: UNICAMP, 22(44), $203-220$.

Ziemann, D. R.; Figueiró, A. (2017a). Diagnóstico do risco de degradação dos geossítios de interesse paleontológico em geossítios da Quarta Colônia (RS). Revista OKARA: Geografia em debate, 11(2), 237-261.

Ziemann, D. R.; Figueiró, A. (2017b). Avaliação do Potencial Geoturístico no Território da Proposta Geoparque Quarta Colônia. Revista do Departamento de Geografia: Universidade de São Paulo, v.34, 137-149. 